\title{
Artificial neural networks modeling of kinetic curves of celeriac (Apium graveolens L.) in vacuum drying
}

\author{
Mohsen BEIGI ${ }^{1 *}$, Iman AHMADI ${ }^{2}$
}

\begin{abstract}
The objective of this study was to predict celeriac drying curves using artificial neural networks (ANNs). The experimental data for vacuum drying kinetics of celeriac slices reported by other researcher in the previously published article was used. The air temperature, chamber pressure and time values were used as ANN inputs. To predict the moisture content, the multilayer feed forward back propagation neural network, as a well-known network, was used. The network with Levenberg-Marquardt learning algorithm, hyperbolic tangent sigmoid transfer function, and 3-6-9-1 topology provided the superior results.
\end{abstract}

Keywords: artificial neural networks; celeriac; drying kinetics; multilayer feed forward back propagation.

Practical Application: In practice, precise predicting of drying kinetics is essential to solve shortcoming of dryers.

\section{Introduction}

Apium graveolens $L$. var. rapaceum is a root vegetable with a bulbous hypocotyl, growing to $120-200 \mathrm{~cm}$ tall. Celeriac is harvested when its hypocotyl is 10 to $14 \mathrm{~cm}$ in diameter. It is source of mineral salts, vitamins ( $\mathrm{K}, \mathrm{C}$ and $\mathrm{E}$ ) and has antioxidant property. Its oil is a remedy for skin complaints and rheumatism (Alibaş, 2012).

Drying agricultural products is one of the oldest methods to store them and prevent them from decay. Safe storage, less volume, longer shelf life, easy packing and transport, improving economical value and producing usage diversity are the advantages of drying (Babalis \& Belessiotis, 2004; Torki-Harchegani et al., 2015). Open sun and shade methods is a traditional drying method that has been employed for the dehydration because of low costs and simplicity. However, these methods have some problems such as microbial contamination of the dried materials, dust as well as long drying time (Soysal, 2004). To overcome these problems, it is essential to employ artificial dryers for the removal of water from agricultural and food products (Demiray \& Tulek, 2012). The type of dryer must be suitable for specific product attributes required. Improper drying causes quality deterioration of product, unreasonable charges, high energy consumption, high process duration, etc. Therefore, food drying is heat sensitive and demands special attention (Mujumdar, 2014).

There are two main types of dryers: direct dryers and vacuum dryers. In the former, hot air at near atmospheric pressure is used to supply the heat to evaporate water or other solvents from the product, but in the latter, a reduced-pressure atmosphere is used to surround the product. Vacuum dryers have some advantages such as: higher drying rate, higher energy efficiency, lower drying temperature and oxygen deficient processing environment compared to direct dryers (Wu et al., 2007). There are some papers on using vacuum drying to dry various food materials and investigations made on the drying kinetics, effect of vacuum drying conditions on drying process and the qualities of dried products (Alibaş, 2012; Bazyma et al., 2006; Jena \& Das, 2007; Zakipour \& Hamidi, 2011).

Many researchers have used mathematical modeling to predict the drying behavior of products being dried, control the drying and design new dryers. These models are divided into three categories e.g., theoretical, semi-theoretical and empirical (Beigi, 2016). Theoretical models are built based on understanding the fundamental heat and mass transfer equations and mechanism during the process whereas the other two are built by fitting model parameters to experimental data using multiple linear regressions (Torki-Harchegani et al., 2015). These models are accurate for the drying process, but they need a computing tool and substantial information about physico-thermal properties of drying materials (Hii et al., 2009). The empirical models are built based on direct correlation between moisture content and drying time. Although these models validate high fitting rates of drying curves in most cases, they neglect fundamentals of dehydration process. The semi-theoretical models are derived from direct solution of Fick's second law by assuming some simplifications, and offer a compromise between theory and ease of application. To date, several researches have reported regression modeling of dehydration kinetics of various biological products such as lemons (Torki-Harchegani et al., 2016), rapeseeds (Han \& Keum, 2011), sweet cherries (Doymaz \& Ismail, 2011), onions (Jafari et al., 2016), pomegranate arils (Minaei et al., 2011), 
potatoes (Amiri Chayjan, 2012), red sea-weeds (Fudholi et al., 2014), mushrooms (Tulek, 2011) and tomatoes (Sadin et al., 2014).

The artificial network (ANN) is a data processing system inspired by biological neural systems and has been used to solve complex and nonlinear problems that have multiple input variables to predict multiple output variables. An ANN learns from examples through iteration without requiring any knowledge of the relationship of the process parameters, and is consequently capable of adapting to a changing environment. If ANNs are employed in an appropriate form, they can provide reasonable solutions in the event of technological faults. Some researchers have utilized the ANNs to simulate drying process of agricultural and food products such as bananas (Mohebbi et al., 2011), seedy grapes (Çakmak \& Yıldız, 2011), paddies (Beigi et al., 2016) and onions (Jafari et al., 2016).

There are many studies about simulation drying process using mathematical models and ANNs but no study has been reported to predict the vacuum drying kinetics of celeriac by ANNs. Therefore, the main objective of the present study was to find the best ANN topology to predict the kinetics of drying celeriac.

\section{Materials and methods}

\subsection{Experimental data}

Alibaş (2012) reported the experimental data for moisture content of celeriac slices during vacuum drying. The data were used to simulate drying process. The researcher dried celeriac slices $57 \mathrm{~mm}$ in diameter and $3 \mathrm{~mm}$ in height. Initial moisture content was $14.39\left(\mathrm{~g}_{\text {water }} / \mathrm{g}_{\text {dry matter }}\right)$ and final moisture content was $0.1\left(\mathrm{~g}_{\text {water }} / \mathrm{g}_{\text {dry matter }}\right)$. The celeriac slices were dried by a vacuum dryer at pressure of $0.1,3,7,10$ and $17 \mathrm{kPa}$ and temperatures of $55,65,75^{\circ} \mathrm{C}$ (Alibaş, 2012).

\subsection{Artificial neural network modeling}

In this study, Neural network tool of MATLAB 2013b (MathWorks, Inc., Natick, MA) was applied to fit the models to experimental moisture content data. Multilayer feed forward back propagation neural network is chosen as the type of ANN. Multilayer feed forward neural networks are popular structures among artificial neural networks widely used to predict and control food processing operations and solve complex problems by modeling input-output relations (Che et al., 2011). The back propagation is a learning algorithm widely used for learning multilayer feed forward neural networks in many applications with the great advantage of simple applications (Choi et al., 2008). Back propagation uses the gradient-descent search method to adjust the connection weight that increases the ANNs accuracy. This learning algorithm has been successfully used by some researchers in various applications, e.g., pattern recognition, location selection and performance evaluations (Bongards, 2001; Che, 2010; Wu et al., 2007).

The input layer of ANN has three parameters: 1) chamber pressure, 2) air temperature and 3) drying time; and the output of the network is moisture ratio. Therefore, for each topology, 3 and 1 neurons were applied to the input and output layers, respectively. Furthermore, the number of neurons in the hidden layer(s) was determined by calibration through several runs. For example, Figure 1 shows a network with topology 3-6-1.

The artificial neural network was trained with 4 methods: 1) scaled conjugate gradient (SCG), 2) Polak-Ribiere conjugate gradient (PCG), 3) BFG quasi-Newton (BFG), and Levenberg-Marquat (LM). Two different kinds of transfer functions were used for neurons in hidden layer(s); 1) hyperbolic tangent sigmoid (Tansig), and 2) log sigmoid (Logsig). The Tansig and Logsig functions are defined in Equations 1 and 2, respectively (Tohidi et al., 2012):

$Y=\operatorname{tansig}(X)=\frac{\exp \left(X_{j}\right)-\exp \left(-X_{j}\right)}{\exp \left(X_{j}\right)+\exp \left(-X_{j}\right)}$

$Y_{j}=\frac{1}{1+\exp \left(-X_{j}\right)}$

Where $X_{j}$ is defined as (Tohidi et al., 2012; Equation 3):

$X_{j}=\sum_{i=1}^{m} W_{i j} Y_{i}+b_{i}$

In these equations, $m$ is the number of neurons in the output layer, $W_{i j}$ is the weight of connections between layers $i$ and $j, Y_{i}$ is the output of the neurons in layer $i$, and $b_{j}$ is the bias of the neurons in layer $j$.

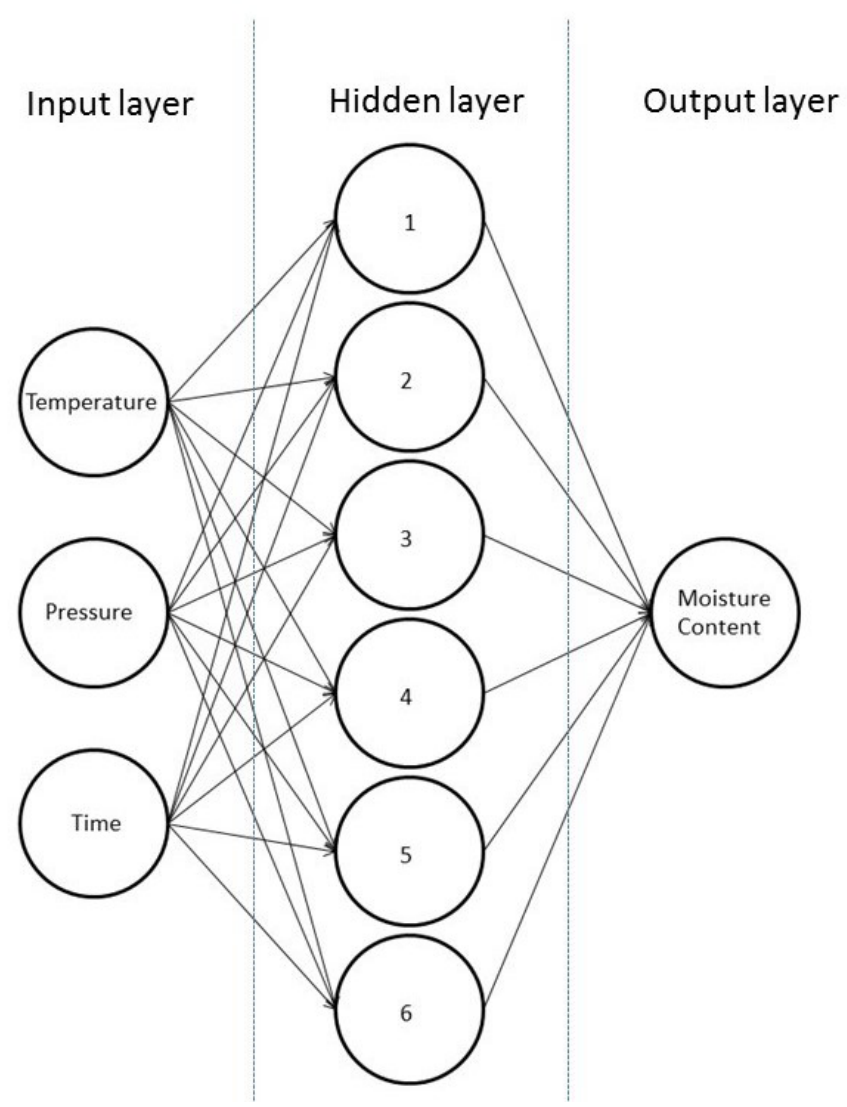

Figure 1. A schematic illustration of neural network with 3-6-1 topology. 
The number of experimental data was 352 divided into three subsets randomly. The majority of them (70\%) were used for computation and updating weights and biases of the network (the training subset). The second (15\%) was used to measure network generalization, and to halt training when generalization stops improving; and the last one (15\%) had no effect on training and so provided an independent measure of network performance during and after training (Zare et al., 2015; Tohidi et al., 2012). The input and output data were normalized between $[-1,1]$ by this Equation 4 (Beigi et al., 2016):

$y=\frac{2\left(x-x_{\min }\right)}{\left(x_{\max }-x_{\min }\right)}-1$

where, $x_{\max }$ and $x_{\min }$ are the largest and the smallest data in given dataset, respectively; and $x$ and $y$ are the no normalized and normalized data, respectively.

The performance of ANNs was determined by mean square error (MSE) (Tohidi et al., 2012; Equation 5):
$M S E=\frac{\sum_{j=0}^{p} \sum_{i=0}^{p}\left(d_{i j}-y_{i j}\right)^{2}}{P N}$

where, $P$ is the number of neurons in output layer; $N$ is the number of samples in the dataset; $y_{i j}$ is the network output for sample $j$ at processing element $j$; and $d_{i j}$ is the desired output for sample $j$ at processing element. The training algorithm was stopped when MSE increased 6 times at the end of training cycles consecutively.

\section{Results and discussion}

Table 1 shows the results of ANNs modeling of the celeriac slices during vacuum drying process. The effects of the number of hidden layers, the number of neurons in each hidden layer, the type of transfer function and the type of training algorithm on precision of moisture content predictions are presented in Table 1. As shown, among the applied networks, the one with a topology of 3-6-9-1, transfer function of Tansig and a LM

Table 1. The results of artificial neural networks modeling in predicting moisture content of celeriac.

\begin{tabular}{|c|c|c|c|c|}
\hline Network topology & $\begin{array}{l}\text { Transfer function } \\
\text { of hidden layer(s) }\end{array}$ & Training algorithm & Number of training cycles & MSE \\
\hline $3-6-1$ & Logsig & SCG & 8 & 8.1644 \\
\hline $3-6-1$ & Logsig & CGP & 45 & 0.22606 \\
\hline $3-6-1$ & Logsig & BFP & 41 & 0.067327 \\
\hline $3-6-1$ & Logsig & LM & 64 & 0.054231 \\
\hline $3-6-1$ & Tansig & SCG & 27 & 0.71245 \\
\hline $3-6-1$ & Tansig & CGP & 17 & 0.51867 \\
\hline $3-6-1$ & Tansig & BFP & 39 & 0.093903 \\
\hline $3-6-1$ & Tansig & $\mathrm{LM}$ & 54 & 0.83465 \\
\hline $3-6-9-1$ & Logsig & SCG & 123 & 0.20627 \\
\hline $3-6-9-1$ & Logsig & CGP & 51 & 0.50672 \\
\hline $3-6-9-1$ & Logsig & BFP & 15 & 0.18641 \\
\hline $3-6-9-1$ & Logsig & $\mathrm{LM}$ & 11 & 0.05508 \\
\hline $3-6-9-1$ & Tansig & SCG & 30 & 0.47816 \\
\hline $3-6-9-1$ & Tansig & CGP & 53 & 0.56405 \\
\hline $3-6-9-1$ & Tansig & BFP & 61 & 0.095496 \\
\hline $3-6-9-1$ & Tansig & LM & 82 & 0.0033437 \\
\hline $3-6-18-1$ & Logsig & SCG & 22 & 1.9313 \\
\hline $3-6-18-1$ & Logsig & CGP & 102 & 0.25456 \\
\hline $3-6-18-1$ & Logsig & BFP & 40 & 0.99962 \\
\hline $3-6-18-1$ & Logsig & LM & 71 & 0.0035701 \\
\hline $3-6-18-1$ & Tansig & SCG & 39 & 0.17031 \\
\hline $3-6-18-1$ & Tansig & CGP & 44 & 0.54634 \\
\hline $3-6-18-1$ & Tansig & BFP & 52 & 0.13435 \\
\hline $3-6-18-1$ & Tansig & LM & 40 & 0.011303 \\
\hline $3-6-36-1$ & Logsig & SCG & 8 & 11.6112 \\
\hline $3-6-36-1$ & Logsig & CGP & 11 & 0.27534 \\
\hline $3-6-36-1$ & Logsig & BFP & 88 & 0.024149 \\
\hline $3-6-36-1$ & Logsig & $\mathrm{LM}$ & 50 & 0.037061 \\
\hline $3-6-36-1$ & Tansig & SCG & 153 & 0.067355 \\
\hline $3-6-36-1$ & Tansig & CGP & 65 & 0.081617 \\
\hline $3-6-36-1$ & Tansig & BFP & 87 & 0.039316 \\
\hline $3-6-36-1$ & Tansig & LM & 19 & 0.015994 \\
\hline
\end{tabular}


training algorithm had better performance with the minimum mean square error. These results are comparable with previous results reported by different researches in the literature. Beigi et al. (2016) found a neural network that had an excellent ability to predict the paddy drying kinetics. This network has 4-18-18-1 topology, transfer function of hyperbolic tangent sigmoid and a Levenberg-Marquat back propagation training algorithm (Beigi et al., 2016). Jafari et al. (2016) examined different topologies to the drying curves of onion slices reported the feed forward back propagation network with topology 2-5-1, Levenberg-Marquat training algorithm, hyperbolic tangent sigmoid transfer function as the best neural network system (Jafari et al., 2016). Zare et al. (2015) investigated combined hot air/infrared drying process and reported that feed forward back propagation neural network with topology of 4-8-14-1, training algorithm of Levenberg-Marquat and a transfer function of hyperbolic tangent sigmoid had the best prediction of drying curves (Zare et al., 2015). Tohidi et al. (2012) showed that Levenberg-Marquat learning algorithm and hyperbolic tangent sigmoid had a good performance to predict drying moisture content of rough rice (Tohidi et al., 2012). Momenzadeh et al. (2012) introduced artificial neural network to predict drying time of green pea in a microwave-assisted fluidized bed dryer and found that a network with Logsig transfer function and back propagation algorithm made the most accurate predictions (Momenzadeh et al., 2012). Yousefi et al. (2013) used artificial neural network to estimate the moisture content of papaya fruit during drying in a cabinet dryer, and reported the multilayer perceptron network with 3-9-1 topology, LM training algorithm and the Logsig transfer function as the best network to predict the drying curves (Yousefi et al., 2013).

To evaluate the performance of the best ANN in modeling celeriac drying curves, the predicted moisture content values were plotted against experimental values (Figure 2). As presented, the ANN could be successfully used to predict moisture content during the drying process. In Figure 3, three different conditions of drying were chosen to show the variation between experimental data and predicted values by ANN. As shown, the experimental points are very close to predicted curves. Similar results were observable for other drying conditions indicating a suitable prediction. Figure 4 shows the histogram of the variations between experimental and predicted values of moisture content of the celeriac slices. 285 cases (more than $80 \%$ of all cases) have errors in the range $[-0.05,0.05]$.
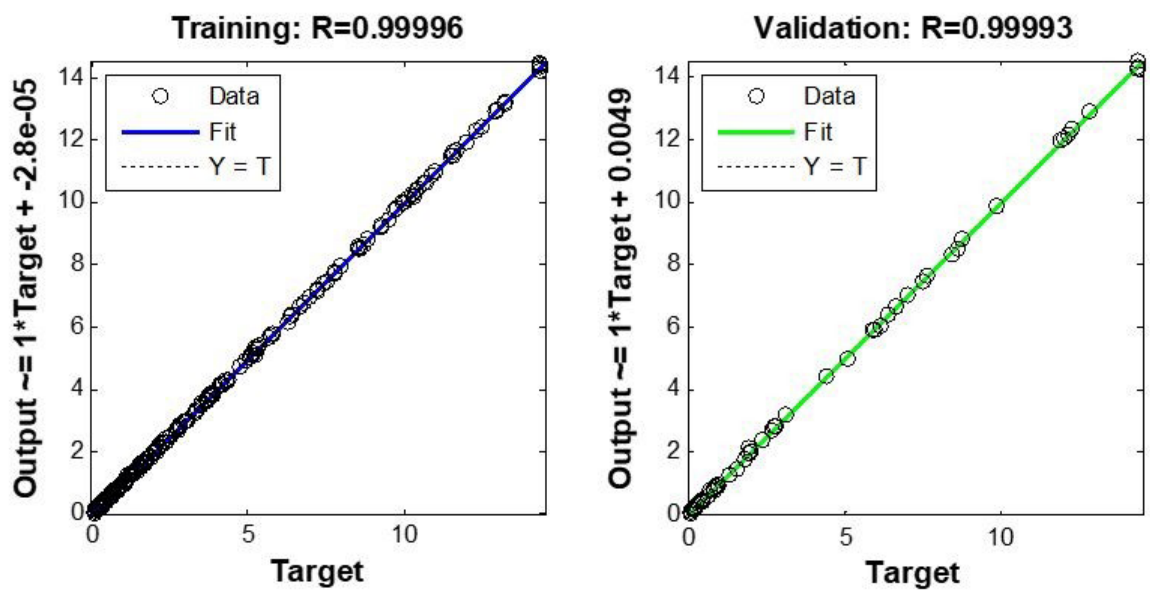

Test: $\mathbf{R}=0.99991$
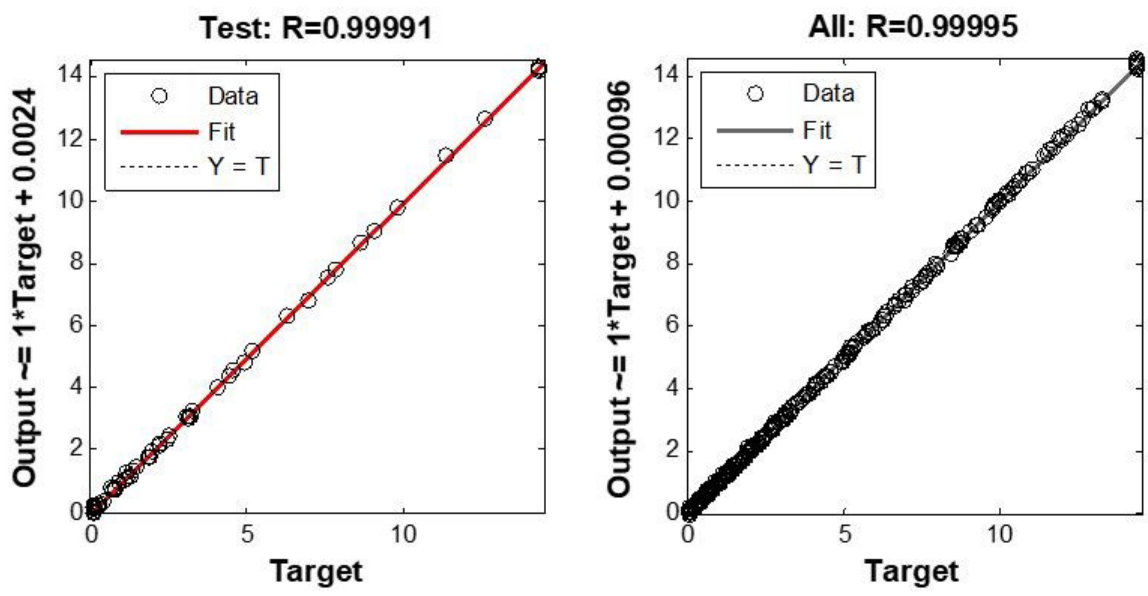

Figure 2. Comparision between exprimental and predicted values of moisture content of the celeriac slices for three datasets (training, validation and test) and all data. 


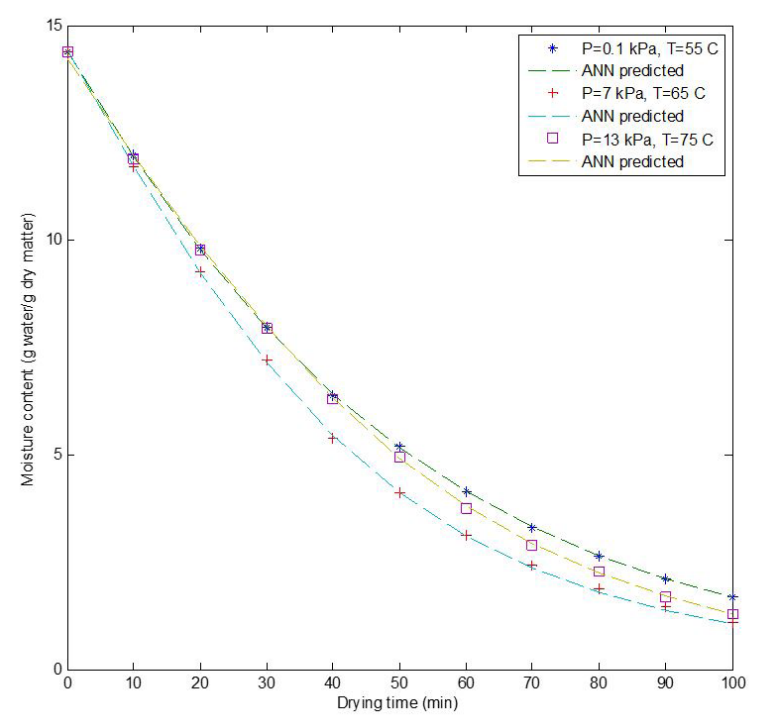

Figure 3. Comparision between moisture content data predicted by the best ANN and the experimental ones for celeriac slices during vaccum drying.

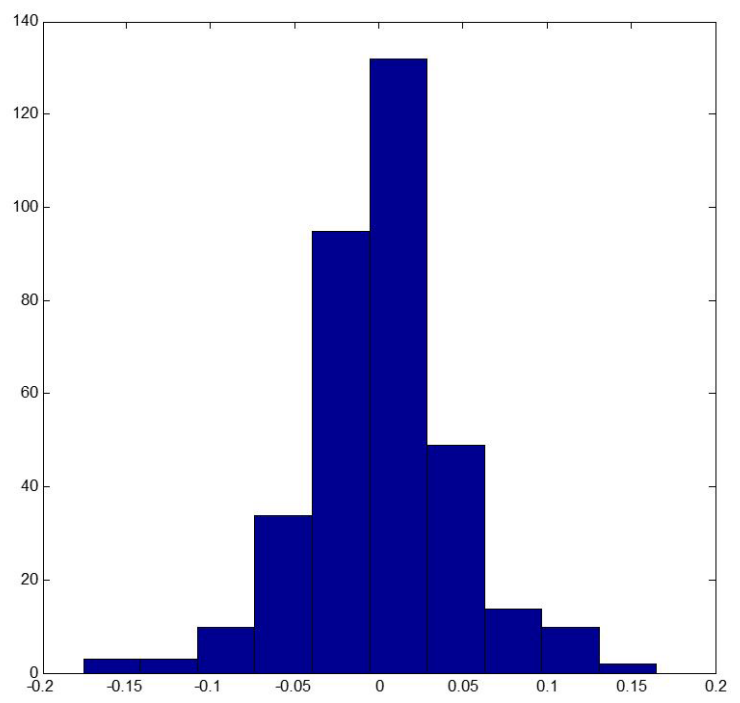

Figure 4. Histogram of error: exprimental values-predicted values predicted using the best ANN.

\section{Conclusions}

Drying data of celeriac slices at six pressure levels $(0.1,3,7,10,13$ and $17 \mathrm{kPa})$ and three temperature levels $\left(55,65\right.$ and $\left.75^{\circ} \mathrm{C}\right)$ were used to find a good artificial neural network that could predict a drying curve. The kind of ANN is chosen Multilayer feed forward back propagation neural, which is examined with four different topologies (3-6-1, 3-6-9-1, 3-6-18-1 and 3-6-36-1), four different learning algorithms (SCG, CGP, BFG and LM) and two different transfer functions (Logsig and Tansig). Finally, the ANN with 3-6-9-1 topology, a Levenberg-Marquat learning algorithm and transfer function of hyperbolic tangent sigmoid had the best performance to predict the variations in the celeriac slices during vacuum drying.

\section{Acknowledgements}

The experimental data used herein for the model verification were acquired from a previously published paper (Alibaş, 2012). The authors greatly appreciate Dr. İlknur Alibaş for the data presented.

\section{References}

Alibaş, İ. (2012). Determination of vacuum and air drying characteristics of celeriac slices. Journal of Biological and Environmental Sciences, 6(16), 1-13.

Amiri Chayjan, R. (2012). Modeling some drying characteristics of high moisture potato slices in fixed, semi fluidized and fluidized bed conditions. Journal of Agricultural Science and Technology, 14(6), 1229-1241.

Babalis, S. J., \& Belessiotis, V. G. (2004). Influence of the drying conditions on the drying constants and moisture diffusivity during the thinlayer drying of figs. Journal of Food Engineering, 65(3), 449-458. http://dx.doi.org/10.1016/j.jfoodeng.2004.02.005.

Bazyma, L. A., Guskov, V. P., Basteev, A. V., Lyashenko, A. M., Lyakhno, V., \& Kutovoy, V. A. (2006). The investigation of low temperature vacuum drying processes of agricultural materials. Journal of Food Engineering, 74(3), 410-415. http://dx.doi.org/10.1016/j. jfoodeng.2005.03.030.

Beigi, M. (2016). Hot air drying of apple slices: dehydration characteristics and quality assessment. Heat and Mass Transfer, 52(8), 1435-1442. http://dx.doi.org/10.1007/s00231-015-1646-8.

Beigi, M., Torki-Harchegani, M., \& Mahmoodi-Eshkaftaki, M. (2016). Prediction of paddy drying kinetics: a comparative study between mathematical and artificial neural network modelling. Chemical Industry \& Chemical Engineering Quarterly, 23, 39.

Bongards, M. (2001). Improving the efficiency of a wastewater treatment plant by fuzzy control and neural networks. Water Science and Technology, 43(11), 189-196. http://dx.doi.org/10.2166/wst.2001.0682. PMid:11443962.

Çakmak, G., \& Yıldız, C. (2011). The prediction of seedy grape drying rate using a neural network method. Computers and Electronics in Agriculture, 75(1), 132-138. http://dx.doi.org/10.1016/j. compag.2010.10.008

Che, Z. (2010). PSO-based back-propagation artificial neural network for product and mold cost estimation of plastic injection molding. Computers \& Industrial Engineering, 58(4), 625-637. http://dx.doi. org/10.1016/j.cie.2010.01.004.

Che, Z.-G., Chiang, T.-A., \& Che, Z.-H. (2011). Feed-forward neural networks training: a comparison between genetic algorithm and back-propagation learning algorithm. International Journal of Innovative Computing, Information, \& Control, 7(10), 5839-5850.

Choi, B., Lee, J.-H., \& Kim, D.-H. (2008). Solving local minima problem with large number of hidden nodes on two-layered feed-forward artificial neural networks. Neurocomputing, 71(16-18), 3640-3643. http://dx.doi.org/10.1016/j.neucom.2008.04.004.

Demiray, E., \& Tulek, Y. (2012). Thin-layer drying of tomato (Lycopersicum esculentum Mill. cv. Rio Grande) slices in a convective hot air dryer. Heat and Mass Transfer, 48(5), 841-847. http://dx.doi.org/10.1007/ s00231-011-0942-1. 
Doymaz, İ., \& Ismail, O. (2011). Drying characteristics of sweet cherry. Food and Bioproducts Processing, 89(1), 31-38. http://dx.doi. org/10.1016/j.fbp.2010.03.006.

Fudholi, A., Sopian, K., Othman, M. Y., \& Ruslan, M. H. (2014). Energy and exergy analyses of solar drying system of red seaweed. Energy and Building, 68, 121-129. http://dx.doi.org/10.1016/j.enbuild.2013.07.072.

Han, J. W., \& Keum, D. H. (2011). Thin layer drying characteristics of rapeseed (Brassica napus L.). Journal of Stored Products Research, 47(1), 32-38. http://dx.doi.org/10.1016/j.jspr.2010.05.006.

Hii, C., Law, C., \& Cloke, M. (2009). Modeling using a new thin layer drying model and product quality of cocoa. Journal of Food Engineering, 90(2), 191-198. http://dx.doi.org/10.1016/j.jfoodeng.2008.06.022.

Jafari, S. M., Ganje, M., Dehnad, D., \& Ghanbari, V. (2016). Mathematical, fuzzy logic and artificial neural network modeling techniques to predict drying kinetics of onion. Journal of Food Processing and Preservation, 40(2), 329-339. http://dx.doi.org/10.1111/jfpp.12610.

Jena, S., \& Das, H. (2007). Modelling for vacuum drying characteristics of coconut presscake. Journal of Food Engineering, 79(1), 92-99. http://dx.doi.org/10.1016/j.jfoodeng.2006.01.032.

Minaei, S., Motevali, A., Ahmadi, E., \& Azizi, M. (2011). Mathematical models of drying pomegranate arils in vacuum and microwave dryers. Journal of Agricultural Science and Technology, 14(2), 311-325.

Mohebbi, M., Shahidi, F., Fathi, M., Ehtiati, A., \& Noshad, M. (2011). Prediction of moisture content in pre-osmosed and ultrasounded dried banana using genetic algorithm and neural network. Food and Bioproducts Processing, 89(4), 362-366. http://dx.doi.org/10.1016/j. fbp.2010.08.001.

Momenzadeh, L., Zomorodian, A., \& Mowla, D. (2012). Applying artificial neural network for drying time prediction of green pea in a microwave assisted fluidized bed dryer. Journal of Agricultural Science and Technology, 14(3), 513-522.

Mujumdar, A. S. (2014). Handbook of industrial drying. Boca Raton: CRC Press. http://dx.doi.org/10.1201/b17208.

Sadin, R., Chegini, G.-R., \& Sadin, H. (2014). The effect of temperature and slice thickness on drying kinetics tomato in the infrared dryer.
Heat and Mass Transfer, 50(4), 501-507. http://dx.doi.org/10.1007/ s00231-013-1255-3.

Soysal, Y. (2004). Microwave drying characteristics of parsley. Biosystems Engineering, 89(2), 167-173. http://dx.doi.org/10.1016/j. biosystemseng.2004.07.008.

Tohidi, M., Sadeghi, M., Mousavi, S. R., \& Mireei, S. A. (2012). Artificial neural network modeling of process and product indices in deep bed drying of rough rice. Turkish Journal of Agriculture and Forestry, 36(6), 738-748.

Torki-Harchegani, M., Ghanbarian, D., \& Sadeghi, M. (2015). Estimation of whole lemon mass transfer parameters during hot air drying using different modelling methods. Heat and Mass Transfer, 51(8), 1121-1129. http://dx.doi.org/10.1007/s00231-014-1483-1.

Torki-Harchegani, M., Ghasemi-Varnamkhasti, M., Ghanbarian, D., Sadeghi, M., \& Tohidi, M. (2016). Dehydration characteristics and mathematical modelling of lemon slices drying undergoing oven treatment. Heat and Mass Transfer, 52(2), 281-289. http://dx.doi. org/10.1007/s00231-015-1546-y.

Tulek, Y. (2011). Drying kinetics of oyster mushroom (Pleurotus ostreatus) in a convective hot air dryer. Journal of Agricultural Science and Technology, 13, 655-664.

Wu, L., Orikasa, T., Ogawa, Y., \& Tagawa, A. (2007). Vacuum drying characteristics of eggplants. Journal of Food Engineering, 83(3), 422429. http://dx.doi.org/10.1016/j.jfoodeng.2007.03.030.

Yousefi, A., Asadi, V., Nassiri, S. M., Niakousari, M., \& Aghdam, S. K. (2013). Comparison of mathematical and neural network models in the estimation of papaya fruit moisture content. Philippine Agricultural Scientist, 95(3), 192-198.

Zakipour, E., \& Hamidi, Z. (2011). Vacuum drying characteristics of some vegetables. Iranian Journal of Chemistry and Chemical Engineering, 30(4), 97-105.

Zare, D., Naderi, H., \& Ranjbaran, M. (2015). Energy and quality attributes of combined hot-air/infrared drying of paddy. Drying Technology, 33(5), 570-582. http://dx.doi.org/10.1080/07373937.2014.962143. 